\title{
Digital Nomad Entrepreneurship and Lifestyle Design: A Process Theory
}

\author{
T. S. Stumpf \\ Humboldt State University \\ ts2158@ humboldt.edu
}

\author{
Christopher B. Califf \\ Western Washington University \\ Christopher.Califf@wwu.edu
}

\author{
Jaime Lancaster \\ Humboldt State University \\ jaime.lancaster@humboldt.edu
}

\begin{abstract}
Advances in information technology have led to the emergence of a digital workforce comprised of several types of workers, one such being the digital nomad. There is an opportunity in to expand the IS literature by investigating the entrepreneurial side of digital nomadism. Digital nomad entrepreneurship (DNE) is a growing phenomenon and distinctive approach to life and entrepreneurship. Previous research has tended to focus on either the lifestyle or business-level aspects of DNE. This study uses grounded theory method to investigate the merger of lifestyle and business factors that combine to form how an individual becomes a digital nomad entrepreneur. The findings reveal a model called the "Digital Nomad Entrepreneurship \& Lifestyle Design Process", which is comprised of four conceptual sub-categories: 1). Pre-Day Zero - Lamentation \& Discovery, 2). Plugging In - Transition \& Acculturation, 3). Just Get Started - 1,000 Messy Days, and 4). The Other Side Mentality Shifts and Scale Lessons.
\end{abstract}

\section{Introduction}

Advances in information technology (IT), combined with the work of some influential business and lifestyle experts, have redefined work $[1,2]$. The result has been the emergence of a specific kind of digital worker: the digital nomad [3,4,5]. Digital nomads are a subset of the digital workforce who "no longer rely on work in a conventional office" [6]. Instead, they live an itinerant lifestyle by working from wherever they wish, provided they have a computer and an internet connection [7]. The desire to become a digital nomad has found its way into popular culture in recent years [8], with increasing interest during the COVID-19 pandemic. For example, a recent article in The Washington Post described an uptick in workers wanting to become digital nomads by describing them as "a privileged class of workers have used the disruption of the pandemic and subsequent surge in remote work to become nomads" [9]. Moreover, companies like Microsoft, Twitter, Spotify, and
Amazon have adopted policies that mirror the lifestyle preferences of digital nomads by enabling employees to work from anywhere, and many of these companies are keeping these policies post-pandemic [10]. Thus, understanding how an individual becomes (and sustains being) a digital nomad is of keen interest to both individuals and organizations.

In information systems (IS), research on digital nomads falls under the umbrella of digital work and the digital workforce $[2,7,11]$. When investigating the digital nomad, IS researchers commonly aim to recognize benefits and drawbacks [7]. For example, Ens et al. [3, p. 6] state: "for the digital nomad, the blending of work and travel, with frequent changes in work spaces and infrastructure, affords a high degree of flexibility and autonomy for the individual. At the same time, it creates challenges in maintaining productivity and feeling competent at work". While the IS discipline has laid a foundation to study and understand digital nomads, it often overlooks investigating the motivations about why individuals desire to become digital nomads, and digital nomads as entrepreneurs. Therefore, there is an opportunity to understand the struggles one experiences sustaining the digital nomad lifestyle, and mapping the process through which this occurs from the perspective of digital nomad entrepreneurs themselves.

The specific aim of the present study is to develop a theoretical model to better understand the process of digital nomad entrepreneurship (DNE). Based on a grounded theory analysis of 27 podcast interviews with digital nomad entrepreneurs, the paper introduces a four-stage model called the "Digital Nomad Entrepreneurship \& Lifestyle Design Process". The model incorporates both philosophical/lifestyle and entrepreneurship considerations through four stages: (1). Pre-Day Zero - Lamentation \& Discovery; (2). Plugging In - Transition \& Acculturation; (3). Just Get Started - 1,000 Messy Days; and (4) The Other Side Mentality Shifts and Scale Lessons. Each stage details characteristics that comprise the DNE journey which can help individuals better understand what it takes to become a digital nomad entrepreneur, and which can 
help companies can better understand a digital and entrepreneurial workforce.

\section{Literature review}

Work and its associated practices are being redefined due to technology in the form of digital work [1]. Digital work has been described in the IS discipline as work that is fundamentally altered by workers using digital technology [2,3]. Because of digital work, there has been understand an emergence of a digital workforce. This workforce enabled by technology affords two fundamental traits: mobility and precarity [3]. Mobility is associated with "multiplicity in work locations" while precarity is associated with "increased insecurity resulting from flexible employment" [3 p. 4]. The digital workforce has been grouped into four types: gig worker, nine to fiver, traveling elite, and digital nomad [3]. This paper focuses on the digital nomad (possessing high levels of mobility and precarity), and more specifically the digital nomad entrepreneur.

Digital nomads can be defined as professionals "who no longer rely on work in a conventional office; instead, they can decide freely when and where to work." [6, p. 344]. The term "digital nomad" was coined in a 1997 book by Makimoto and Manners [12], who posited that advances in mobile technology would allow humans the opportunity to reengage with "urges inherited from nomadic ancestors" (p. 2) by breaking the modern imperative of being tethered to a static geographic location. As the authors correctly predicted, "with the ability to tap into every worldwide public information source from anywhere on the globe, and the ability to talk to anyone via a video link, humans are going to be given the opportunity, if they want it, of being global nomads" [12, p. 6].

For the next decade, these ideas dwelt in relative obscurity. On April 24, 2007, these ideas were brought to life in the public consciousness with the publication of the book The 4-Hour Work Week: Escape 9-5, Live Anywhere, and Join the New Rich. The book, written by entrepreneur Tim Ferriss, became a philosophical and practical touchstone for the digital nomad revolution. In the book, Ferriss [8, p. 7] provides a roadmap for avoiding "resignation to 9-to-5 drudgery in exchange for (sometimes) relaxing weekends and the occasional keep-it-short-or-get-fired vacation". Ferriss [8, p.7] refers to this process as "an art and a science we will refer to as Lifestyle Design". Those who embrace this approach are dubbed "The New Rich", or those who can successfully shed status quo ideas about the nexus of life and work, and can optimize for time and global mobility through digital entrepreneurship. While "The New Rich" term never quite caught on in public parlance, individuals who started to adopt this approach became commonly known as digital nomads.

The phenomenon of DNE is currently situated at a pivotal position in public consciousness. On one hand, public awareness of DNE has never been higher. As the number of people exploring DNE has grown, the array of YouTube channels, blogs, books, courses, and podcasts focused on providing information on DNE has expanded accordingly. On the other hand, DNE continues to occupy a relatively obscure place in the consciousness of mainstream culture generally, and the conventional business community more specifically. This includes the world of postsecondary business education [13]. For example, while it is now more common for business departments to offer courses on digital marketing and/or e-commerce entrepreneurship, it is quite rare for a holistic exploration of the DNE paradigm to be covered in these courses. Such an exploration would include not only the practical tools and techniques important for starting an online business, but would integrate provision for the other aspects of DNE, including philosophical and existential explorations, global travel acumen, and practical strategies for designing one's life and business for location-independence (to name a few).

There also remains a gap in the literature regarding the entrepreneurship-level aspects of digital nomadism. Instead, scholars have focused on more philosophical, lifestyle, and sociological aspects of DNE, including defining the phenomenon $(6,14,15]$, lifestyle considerations of digital nomads [16], exploring issues relating to self-presentation and authenticity [17], digital nomad mobilities [18], the role of co-living and co-working spaces on digital nomads' well-being $[19,20]$, the role of disciplining in managing work/life boundaries in digital nomadism [21], and investigations into the sociocultural imaginaries of digital nomadism [22].

At the same time, research on digital entrepreneurship focuses on the business-level aspects of starting and operating an internet-based venture, but does not do so in ways which account for how these intersect with the more philosophical, lifestyle, and sociological aspects of DNE discussed above. The absence of provision for the latter in favor of the former is evident in the definitions of digital entrepreneurship found in the literature. For instance, Hull et al. [23 p. 293] state "digital entrepreneurship is a subcategory of entrepreneurship in which some or all of what would be physical in a traditional organization has been digitized." Hair et al. [24, p. 2] similarly offer that "digital entrepreneurship may be defined as entrepreneurship in which some or all of the 
entrepreneurial venture takes place digitally instead of in more traditional formats." In a final example presented here, Sussan and Acs [25, p. 66] state that digital entrepreneurship "includes any agent that is engaged in any sort of venture be it commercial, social, government, or corporate that uses digital technologies."

However, practically speaking, successful digital nomad entrepreneurs are not simply wistful globe trekkers who have rejected status quo social conventions and effortlessly receive passive income with a few clicks on a laptop under the shade of a coconut tree. Also, they are also not simply "agents" who exploit market opportunities to generate revenue through the sale of products and services across digital networks. Instead, digital nomad entrepreneurs are individuals who undergo a profound period of selfexploration to embrace an idiosyncratic approach to life and work. To understand digital nomad entrepreneurs, research must bridge the disconnect between the more philosophical/lifestyle and entrepreneurial aspects of DNE. This study helps to build that bridge by developing a grounded theoretical model which accounts for both, thus offering a more balanced understanding of DNE to the literature.

\section{Method}

Classic grounded theory method (GTM) [26,27] was used to address the theory development aims of this paper. Due to its theory development utility, GTM has become accepted as an effective method for developing field-specific theory in business more generally [28], and on topics related to technology and information systems more specifically [29,30]. GTM is characterized by an inductive approach of simultaneous data collection and analysis, whereby no a-priori predictions or assumptions are made about what the data will reveal. Instead, data codes, conceptual categories, and theoretical insights are allowed iteratively to emerge from the data through a process of constant comparison [27]. Ontologically, GTM is focused on systematically examining how subjects interpret the reality of a particular social domain, and thus can be a considered a middle ground between empiricism and relativism [26]. Classic GTM was selected because it was deemed to offer the combination of systematic rigor and interpretive potential most amenable to both the researchers' style, as well as the theory development aims of this underexplored research area.

\subsection{Data collection and analysis}

Interviews have typically been used as the primary method of data collection in GTM research. As Glaser and Strauss [27, p. 162] state, scholars' "preference for using data produced by themselves...is due to the traditional stance, at least in America, against confusing history - conceived as a humanistic field with social science." As such, some qualitative scholars "have never seriously considered" alternative sources of "real data for their work... [or] distrust their own competencies in discovering and working with library materials as primary data" [27, p. 163]. However, these founders of GTM also state that researchers "need to be as skilled and ingenious in using documentary materials as in doing field work. These materials are as potentially valuable for generating theory as our observations and interviews" $[27$, p. 163]. A central methodological tenet of the present research is summarized in the following passage from Glaser and Strauss [27, p. 163]:

When someone stands in the library stacks, he is, metaphorically, surrounded by voiced begging to be heard. Every book, every magazine article, represents at least one person who is equivalent to the anthropologist's informant or the sociologist's interviewee. In those publications, people converse, announce positions, argue with a range of eloquence, and describe events or scenes in ways entirely comparable to what is seen and heard during field work. The researcher needs only to discover the voices in the library to release them for his analytic use.

As opposed to primary interview data, the present study utilized the digital library of podcast interviews with digital nomad entrepreneurs as the source of data collection. With the growing popularity of both DNE and podcasts, as well as the growing number of podcast hosting platforms, an array of podcasts specifically focusing on digital nomad entrepreneurship has emerged. This application of GTM to explore this digital cache of secondary interview data, although novel, aligns with the core tenets of this established research methodology.

The data collection process started by browsing the library of three well-known podcasts related to DNE. This produced a total of 1,416 total episodes. The search was narrowed down to episodes which featured interviews with digital nomad entrepreneurs (as opposed to podcast host commentary or analyses on issues related to DNE). Through an initial listening and coding process, it was clear that the three different podcasts had different thematic approaches to the interviews. Two were exclusively focused on the more technical business aspects of digital entrepreneurship, while the other was focused on both the lifestyle and 
business aspects of DNE. In that the latter is the focus of the present study, the decision was made to utilize the interview library of one podcast exclusively. This podcast was "The Tropical MBA Podcast", which refers to itself as "The podcast for locationindependent business owners." This decision to standardize the data collection to one podcast which aligned well with the focus of this study also helped reduce potential "noise" stemming from variation in interview styles and approaches.

A total of 27 interviews were utilized in the data collection and analysis. The length of the interviews ranged from 24 to 52 minutes (mean $=40.6$ minutes; median $=45$ ). The date of the interviews ranged from 2015 to 2021, and featured digital nomad entrepreneurs with nationalities from seven different countries. The majority of the interview subjects were American $(74 \%)$, and the total number of different countries where these subjects had lived while running their location-independent businesses was 12, including Columbia, Thailand, Taiwan, Vietnam, Brazil, Japan, New Zealand, the United States, Chile, Cambodia, Philippines, and Bali. Of these, Thailand and Bali were the most common. The number of years these individuals had been operating their businesses ranged from 4 to 10 years $($ mean $=7.8$; median $=8)$, and the types of digital business they operated included productized services, e-books, affiliate marketing sites, e-courses, e-services, e-commerce retail, blogs, and software as a service.

3.1.1. Open coding. The data analysis started with open coding, which is about "running the data open" [26, p. 56] to develop initial clarity about what is happening in the data, and how data incidents relate to emerging categories of concepts. A total of 760 initial data incidents were examined. Constant comparison was utilized to compare data incidents with previous codes. This served to refine codes and iteratively consolidate groups of codes together into higher levels of conceptual abstraction. Through open coding, a core conceptual category is eventually identified as the main focus of the research.

A total of 83 separate codes were generated through open coding. Conceptual memoing was used to develop ideas about the codes and their interrelationships [26]. These memos began to reveal a distinct process that often characterizes DNE. As such, the on-going data collection and analysis adopted a process approach epistemology that emphasized understanding how things develop over time [31]. While ideally, research adopting more of a process approach will utilize longitudinal data, the practicalities of this can be prohibitive for most [32]. While the interview data of the present research is not longitudinal in the technical sense, the questioning probed issues which invited subjects to provide insights and narrative accounts spanning a wide temporal range of their entrepreneurship journey. This was deemed a reasonable approach for gaining insights into how key events relative to the research question unfolded over time.

In assessing the codes and conceptual themes that had developed to that point in the coding [26], the "Digital Nomad Entrepreneurship \& Lifestyle Design Process" was selected as the core category of the research. This met the criteria of a core category in that it: (1) appeared centrally positioned, (2) occurred frequently, (3) had potential connections to a rich set of sub-categories, and (4) had clear implications for a relevant theory on the research topic [26]. The focus then shifted to delimiting this process in the ongoing data collection and analysis through selective coding.

3.1.2. Selective coding. Selective coding was then used to hone in on the concepts relevant to the "Digital Nomad Entrepreneurship \& Lifestyle Design Process". This typically relies on theoretical sampling, which allows decisions about subsequent sources of data collection to be directed by theoretical relevance to the emerging grounded theory [26]. Given that the present research utilized secondary rather than primary interview data, the theoretical sampling process occurred only at the start of the research (as described previously), as opposed to iteratively throughout.

In the selective coding phase, a four-stage temporal sequence began to emerge. Ensuing data incidents and codes began to be subsumed under each stage as conceptual properties. The four conceptual sub-categories that comprise this sequence were named: 1). Pre-Day Zero - Lamentation \& Discovery, 2). Plugging In - Transition \& Acculturation, 3). Just Get Started - 1,000 Messy Days, and 4). The Other Side - Mentality Shifts and Scale Lessons. Figure 1 illustrates the process of moving from data incidents to open codes to selective codes to a conceptual subcategory in the substantive coding process. 


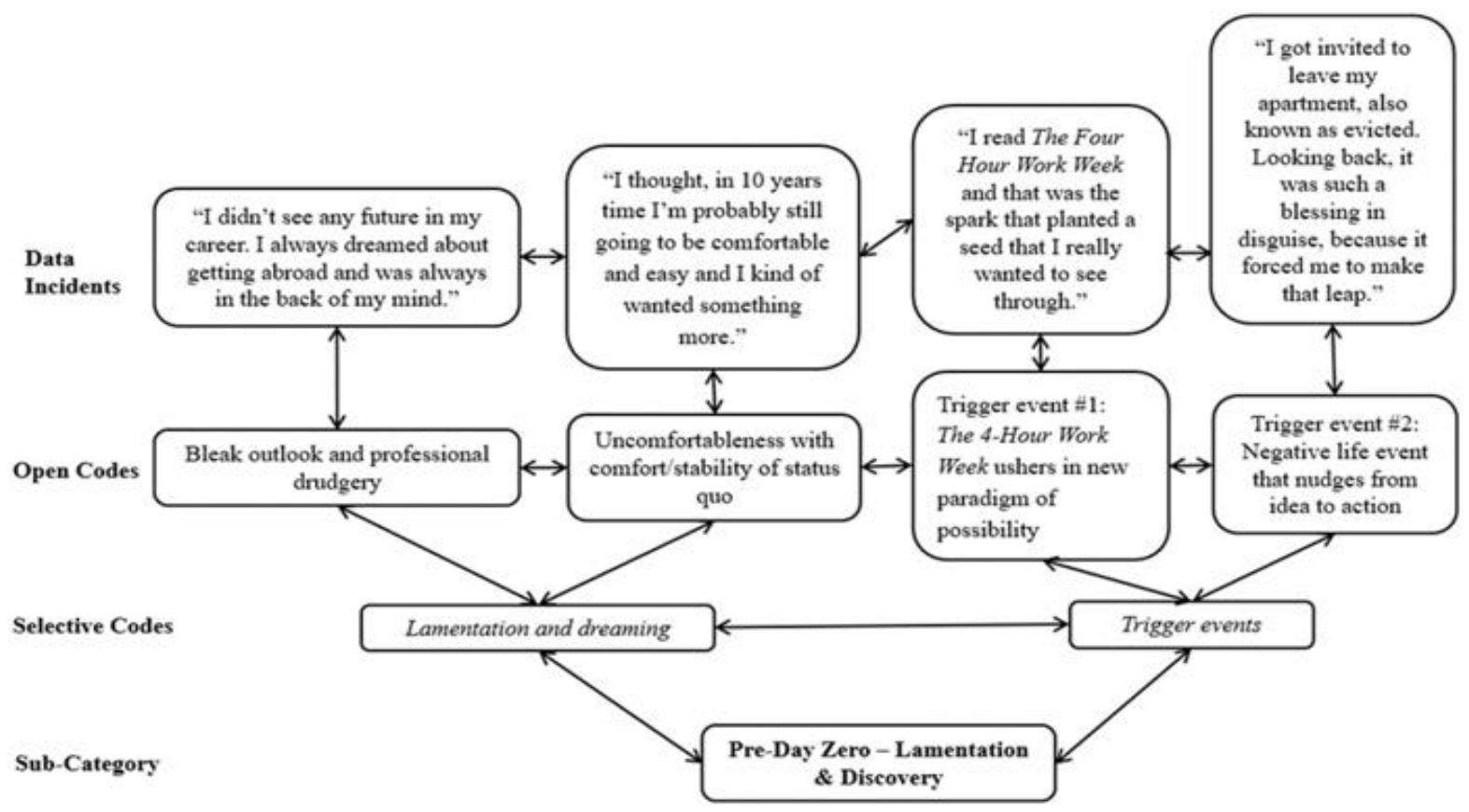

Figure 1. Sample of the substantive coding process using the Pre-Day Zero - Lamentation \& Discovery sub-category

3.1.3. Theoretical coding. In GTM research, data collection stops when conceptual saturation has been reached. This is the point at which concepts and categories have been developed, the data collection and analysis begins producing redundant results, and no new conceptual insights are being produced. It was determined that saturation had occurred after the 27th interview, and the focus thus shifted to theoretical coding, an implicit process where "one talks substantively and thinks theoretically of the relationship between codes" [26, p. 72]. This is accomplished by relating codes to each other conceptually as part of organized theoretical framework. The results of the theoretical coding are presented next.

\section{Findings and discussion}

\subsection{Sub-Category 1: Pre-Day Zero - Lamentation \& Discovery}

The digital nomad entrepreneur typically conjures up images of an adventurous young adult running their business in sandals and shorts on their laptop from an internet café by the beach. Or as Cook [21, p. 355356] states, those who "reject outwardly imposed structures of traditional office work", and challenge "work/leisure boundaries in the pursuit of freedom". While this can be accurate, our results suggest that for many the path leading to DNE is frequently paved in banality, discontent, and even desperation. These ideas were captured in the conceptual sub-category "Pre-Day Zero - Lamentation \& Discovery".

This phase is characterized by discontent and disappointment with a career and lifestyle built in accordance with societal expectations. This discontent was captured in codes such as "Bleak outlook and professional drudgery", "This is no way to live - must be more to life", and "Not seeing the value of my current life". Subjects often reported stable, yet emotionally unfulfilling professional and personal situations that left them feeling somewhere on a spectrum between apathy and misery. While previous work suggests digital nomads rarely begin their journey worrying about burnout [21], the findings here suggest that burnout of their current situation played a role in this first stage of their DNE process. As one subject stated:

I was in a corporate job...I had my cubicle and computer. I remember the highlight of my day, I would go across the street and buy a muffin, and I thought, that's no way to live...I can remember having that Sunday night dread where you can't even enjoy the end of your weekend because you're starting your job that you absolutely hate the next day.

Interestingly, subjects reported that these same situations, gloomy as they were, were instrumental to the eventual success of their businesses after the transition to DNE. Codes such as "Unknowingly building crucial digital entrepreneurship skills in 9-5 career", "Real world MBA", and "Engrained values of responsibility and professionalism from 9-5 career" are 
representative of the crucial role that these professional experiences played in helping to build the skills relevant to subsequently operating digital ventures. Such skills included sales, customer service, task management, responsibility, and basic professionalism. As one subject stated:

I didn't realize it at the time, that I was just kind of picking up on stuff like how to talk to customers over the phone, how to manage employees... Looking back on that, I guess that's kind of the seeds of the entrepreneurship thing.

Being mired in suboptimal careers also prompted an important process of dreaming for these future digital entrepreneurs. These ideas were captured in codes like "Dreaming of unknown alternative" and "Desire for self-indulgence", whereby subjects described a longing for some escape from their current circumstances, but lack of knowledge on what that could be. Two interrelated types of trigger events that propelled these individuals from lamentation to discovery were reported. The first was coded as "Trigger event \#1: The 4-Hour Work Week ushers in new paradigm of possibility". As mentioned above, the book is often touted as the philosophical and practical touchstone for the digital nomad community. Indeed, a large percentage of the subjects of this study pinpointed the book as a major factor in shifting their perspective about what's possible, and as one subject stated, "illuminating an alternative path". As one explained:

I read The 4-Hour Workweek... that little spark definitely planted a seed that I really wanted to see through.

However, subjects also commonly reported that the book alone was not enough to prompt a career and lifestyle change towards DNE. Rather, it planted a seed that was fertilized by the second trigger event, coded "Trigger event \#2: Negative life event that nudges from idea to action" which disrupted the status quo and forced them to reckon with the unfulfilling nature of their lives. Many subjects reported watershed moments such as evictions, firings, break-ups, and other particularly distressing experiences as the pivotal instances which motivated them to put the ideas of The 4-Hour Work Week into action. One subject stated:

I got invited to leave my apartment, also known as evicted. Looking back, it was such a blessing in disguise, because it forced me to make that leap.
Due to the lack of formal entrepreneurship education and experience reported by the vast majority of subjects, the next steps after these trigger events typically included what was coded "Independent learning - consuming books, podcasts, and courses about starting an online business". At the same time, subjects began researching ways to begin their international journey (coded "Looking for the initial passport abroad"), and searching for ways to break free of externally imposed standards of life and work (coded "Overcoming social stigma and family pressure").

\subsection{Sub-Category 2: Plugging In - Transition \& Acculturation}

Following the period of discontent and discovery of DNE, subjects entered a transitional phase during which they became integrated into the DNE community. This process is described in the next temporal sub-category named "Plugging In: Transition \& Acculturation."

Being a digital nomad is associated with a newfound abundance of personal choice and freedom [33], living and moving with fluidity and without a home base [7], and earning a personal income in ways which optimize for self-determination and autonomy [15]. While some previous work has explored some communal aspects of digital nomadism [20], there has been less of a recognition of the role of networks in helping individuals plug into and acculturate to the DNE community prior to the development of their actual location-independent business. The results here indicate this often begins with getting abroad and/or going online and finding communities of likeminded individuals. Subjects often reported purchasing oneway tickets to digital nomad hubs (i.e., Thailand, Bali, Colombia, Vietnam, the Philippines) with either a vague plan, or no plan for what might come next. However, many subjects also described how prior to departure, they discovered online DNE discussion sites which provided them locations where digital nomads were congregating, thereby providing information on an initial point of contact upon arrival. These ideas were captured in codes like "Get online and get abroad", "Plugging into the community", and "Finding likeminded people". As one subject explained:

The 4-Hour Work Week was ringing between my ears... and I met someone and he said, 'Oh, you got to join [this community of digital nomad entrepreneurs] ...he picked me up from my hotel on a motorbike and took me straight to a friend's house who was hosting this coworking event. And I immediately plugged in to the community within hours of landing. 
Subjects described how the DNE community provided mentoring services and, as one subject stated, "showed me the ropes of operating this kind of business". Keeping in mind that most of the subjects reported having little or no business education or direct entrepreneurship experience, this process of networking and subsequent mentorship was invaluable at these initial stages of business development. This was captured in codes like "Helping to overcome doubt", "Allowing oneself to dream that big", and "Demystification of DNE".

In addition to mentorship, subjects described an acculturation process whereby current digital nomad entrepreneurs would help socialize the subjects around the norms of the community, and provide lifestyle guidance. These ideas were captured in codes like "Took me under their wing" and "Let me know I was one of them". Not only did this process help fortify their new identities as a member of the DNE community, but subjects reported how this allowed them to "overcome doubt" and make the "decision to go all in." These "moments of truth" as some labeled them, marked the transition from idea to action. Stated differently, this was the beginning of their 1,000-day journey.

\subsection{Sub-category 3: Just Get Started - 1,000 Messy Days}

One of the most prevalent themes in the interviews for this research was what was commonly referred to as "the 1,000-day principle" - the idea that it takes roughly 1,000 days to build a viable digital enterprise. This idea seems to be well-known as an important heuristic of DNE among this community. In many ways, the 1,000-day principle provides a needed balance to The 4-Hour Work Week which often implies a digital nomad promise land characterized by a globetrotting life of leisure and wealth. In reality however, as the subjects here regularly reiterated, the road to eventual DNE success often involves roughly 1,000 days of struggle and financial uncertainty.

Subsequent to the decision to go all in on DNE, subjects repeatedly described one of the single most important aspects of creating a viable digital business, which was captured in the code "Just get started". As opposed to perfecting the product/service offering, subjects reported using a lean start-up [34] approach of getting the initial offering out to customers, getting customer feedback, and iteratively improving subsequent offerings based on that feedback.

Relatedly, what was referred to as the "stairstep approach" was also frequently mentioned throughout the interviews. Attributed to entrepreneur Rob
Walling, the stairstep approach advocates for starting at the bottom of the DNE staircase by offering one product/service through one sales channel. This helps to reduce complexity and overload at the beginning phase of one's entrepreneurship journey, particularly for those with no prior experience. Once honed, this process should be repeated, and thus one moves up the staircase by incrementally adding products/services and channels only when the previous have been mastered. Eventually, the goal is to reach the top of the staircase, characterized by automated processes and recurring monthly revenue.

The data here suggest that how these entrepreneurs manage to meet their financial needs at the beginning and middle of the staircase is captured in the code "Leveraging currency differences". This code captures the practice of choosing low cost-of-living locations to operate the business from in the early stages of the business where profitability is either very modest, zero, or negative. For instance, one subject described how she was making a rather paltry $\$ 600$ per month six months after launch, but which was enough at that point in her staircase because her cost of living in Thailand was roughly the same. As subjects grew their businesses and reported higher net income, they were able to travel to locations with higher costs-of-living.

While leveraging currency differences to incrementally ascend one's entrepreneurial staircase over the course of 1,000 days sounds straightforward, the results indicate a messiness to this process characterized by doubt, struggle, and angst. This aligns with the high levels of precarity which characterizes digital nomadism pointed out by previous work [3]. These ideas were captured in codes such as "Urgency have to make this work to survive", "Worry about running out of money and having to go back home a failure", and "Taking longer than expected". Almost all subjects reported points in the 1,000 days of not seeing a viable way forward with the business, and seriously contemplating giving up. Looking back, these subjects reported that what got them and the business through this period was comprised of four main things. The first was a deep desire and commitment combined with tenacity and perseverance. Second was a deep commitment learning. This was captured in codes such as "Learning not earning" and "Skills to succeed not taught in universities". Third, subjects reported doubling down on "growth hacking" strategies such as utilizing social media to connect with customers, engaging in online communities and forums, partnerships and collaborations, guest posting on blogs, doing giveaways, appearing on podcasts, and leveraging YouTube as a sales funnel. The final factor subjects reported was captured in the code "Found the lever that finally accelerated the business". Subjects 
often described one or two key factors that made a disproportionately large impact in helping to turn the business towards greater viability. This led to the final code organized under this sub-category, "Hockey stick growth". On account of discovering the levers that catapulted the business forward, subjects reported growth that was stagnant for an extended period, followed by a sharp increase in revenue. Plotted on a graph, this resembles a hockey stick. This sudden and sharp growth led into the fourth and final temporal phase, described next.

\subsection{Sub-Category 4: The Other Side - Mentality shifts and scale lessons}

After the eventual validation of the business, subjects reported shifts in both the operation of the business, and lifestyle aspects of their DNE journey. This was often described as "emerging on the other side" of the first 1,000 days, and included ideas captured in the final temporal sub-category "The Other Side: Mentality Shifts and Scale Lessons”.

The data suggest six common mentality shifts in this phase. The first was captured in the code "Mentality shift - From relief of validation to angst about how to sustain." This reinforces the ideas of previous research on the role in discipline in DNE [21] which states that, contrary to the common stereotype of digital nomads, there is no easy ride in DNE. Rather, like any good business, founders of digital ventures spent little time basking in the relief that their business has proven viable, and instead immediately shifted their focus to how to sustain the business long-term. This often prompted what was coded "Mentality shift From running a business to building an asset." This coincided with what was coded "Mentality shift: Separating my identity from the business".

Subjects often described a process of realizing a need to work "on the business" rather than "in the business" in order to shift the business toward something that could be sustained with less inputs from the founders themselves. Subjects frequently described a shift in viewing the business as an asset that could be build up through codified processes and standard operating procedures. This shift also included what was coded "Mentality shift - From clients to customers". To help the business remain sustainable with fewer inputs from the founder, subjects described moving from higher-touch to lower-touch customer relationships. As opposed to creating customized products and services and time spent on individual interactions, subjects described how they began to offer products/services with a more clearly defined scope in order to optimize time by making the customer interaction process less relational and nuanced, and more transactional and straightforward.

This mentality shift from operating a business to building an asset combined with the shift from clients to customers, and with the shift of separating one's identity from the business led to the first of several key scale lessons that emerged from the data. These were coded "Scale lessons - Doing everything yourself will not scale, build processes" and "Scale lessons Outsource the work and up-level the team". Decisions about what to outsource and/or automate, and what to do oneself were captured in the code "Scale lessons 80-20 discovery". The 80-20 rule, also known as Pareto's Law, is the idea that $80 \%$ of outcomes flow from $20 \%$ of inputs. As one subject described:

Figure out your 80-20, and where you should be focusing your energy. Whatever your business type is, $20 \%$ of what you do is going to generate $80 \%$ of your income, and if you can keep sorting the wheat from the chaff that actually massively pays off.

The final set of scale lessons were more philosophical. The first was coded as "Scale lessons: It's never quite enough (experiencing hedonic adaptation)". Hedonic adaptation is the tendency for humans to return to a baseline level of happiness following a positive or negative life event. One of the first studies on hedonic adaptation was on recent lottery winners by Brickman et al. [35], who found that after 18 months these individuals had returned to a happiness level that was not significantly different than those who had not experienced a large windfall. Subsequent research on topics ranging from marriage [36] to employment decisions [37] have found similar results. The subjects of the present study expressed this same sentiment when prompted to reflect on lessons learned while scaling their business. Interestingly, they seemed keenly aware of the fallacy that more sales and constant growth would bring increasing levels of happiness, and seemed to strategically adopt a measured approach to scaling their business that balanced lifestyle considerations. These ideas were captured in codes like "Scale lessons: If you always chase more, how will you enjoy your life?" and "Scale lessons - don't grow for growth's sake". As one subject described:

I love this lifestyle for the freedom it affords me...the freedom is still my modus operandi. That is for sure what I do all of this for. Every time I think about doing something to make more money I think about how much more freedom is this going to buy me. And freedom for me is the ability to live where I want, when I want. And that's really my driving force. 
While the precise reasons for this was not explained, it may be that the DNE community has a set of shared information resources that acculturate these entrepreneurs to these ideas that generally differ from more mainstream entrepreneurship communities on issues relating to continuous growth. By adopting a more measured approach, the subjects described being able to better balance time spent on their business with time engaging in other aspects of their lives, which was captured in the code "Scale lessons: Structuring time in ways which align with my values". As one described:

Where I am now...this was the goal for me. This was the dream lifestyle. To be somewhere, to have my own business, to be able to travel where I want when I want, and to be building something that I know is sustainable.

\section{Conclusion}

The literature on DNE has focused mostly on lifestyle aspects [33], whereas the literature on digital entrepreneurship has focused mostly on business and technology use. The present study bridges this gap by recognizing that DNE is a process whereby lifestyle considerations, business acumen, and technology utilization blend together to create this unique form of entrepreneurship. The process that emerged in the data collection and analysis of the present study is unique to the literature in that it recognizes the critical life events that precede DNE, the transition phase into DNE, how these are transformed into entrepreneurial activity, and the trajectory this often facilitates. The results suggest that building a successful location-independent business often follows a fairly systematic temporal sequence of lamentation of current life/professional circumstances and discovery of DNE as an alternative, followed by transition and acculturation into the DNE community, a roughly three-year phase of starting and growing a business, and emerging with some important mentality shifts and scale lessons that allow one to sustain the business in the long term. With the increasing focus on remote work, intensified by the Covid-19 pandemic, this process theory provides a practical guide for aligning income generation with a more mobile, flexible lifestyle, and for those who yearn to be liberated from the traditional workplace.

These conclusions should be evaluated in light of some limitations of this study. Ideally, more than one podcast would be used for data collection in order to evaluate a broader sample of subjects. Future studies may also include in-depth analysis of demographic information to explore how these variables may introduce variation into the process theory.

\section{References}

[1] A. Colbert, N. Yee, and G. George, "The Digital Workforce and the Workplace of the Future," Academy of Management Journal, vol. 59, no. 3, 2016, pp. 731-739.

[2] W. J. Orlikowski and S. V. Scott, "Digital Work: A Research Agenda" In A Research Agenda for Management and Organization Studies, (B. Czarniawska, Ed.). Edward Elgar, Cheltenham, UK, 2016.

[3] N. L. Ens, M. K. Stein, and T. B. Jensen. "Decent Digital Work: Technology Affordances and Constraints." Copenhagen Business School. Accessed October 20, 2020. https://www.researchgate.net/publication/329450302_Decent _Digital_Work_Technology_Affordan ces_and_Constraints, 2018.

[4] M. H. Jarrahi, , G. Philips, W. Sutherland, S. Sawyer, and I. Erickson, "Personalization of Knowledge, Personal Knowledge Ecology, and Digital Nomadism," Journal of the Association for Information Science and Technology, vol. 70, no. 4, 2019, pp. 313-324.

[5] J. D. Prester, D. Cecez-Kecmanovic, and D. Schlagwein, "Becoming a Digital Nomad: Identity Emergence in the Flow of Practice", 40th International Conference on Information Systems, 2019.

[6] A. Müller, A, "The Digital Nomad: Buzzword or Research Category?," Transnational Social Review: A Social Work Journal, Vol. 6, no. 3, 2016, pp. 344-348.

[7] C. Nash, M. Hossein-Jarrahi, W. Sutherland, and G. Phillips, "Digital Nomads Beyond the Buzzword: Defining Digital Nomadic Work and Use of Digital Technologies" In Transforming Digital Worlds (G. Chowdhury, J. McLeod, V. Gillet, and P. Willet, Eds), pp. 207-217, Springer, Berlin, 2018.

[8] T. Ferriss, The 4-Hour Work Week: Escape 9-5, Live Anywhere, and Join the New Rich, Harmony, New York, 2007.

[9] J. D. Shadel, "Like summer camp for grown-ups: The pandemic is changing the digital nomad scene," Accessed June 1, 2021,

https://www.washingtonpost.com/travel/2021/02/22/digitalnomad-visas-covid/, 2021.

[10] J. Dickler, "For Better or Worse, Working from Home is Here to Stay," Accessed June 1, 2021, https://www.cnbc.com/2021/03/11/one-year-into-covidworking-from-home-is-here-to-stay.html, 2021.

[11] K. Lyytinen, and Y. Yoo, "Research Commentary: The Next Wave of Nomadic Computing," Information Systems Research, vol. 13, no. 4, 2002, pp. 377-388. 
[12] T. Makimoto and D. Manners, Digital Nomad. Wiley, Chichester, 1997.

[13] S. Kraus, C. Palmer, N. Kailer, F. L. Kallinger, and J. Spitzer, "Digital Entrepreneurship: A Research Agenda on New Business Models for the Twenty-First Century," International Journal of Entrepreneurial Behavior \& Research, vol. 25, no 2, 2019, pp. 353-375.

[14] I. Hermann and C. M. Paris, "Digital Nomadism: The Nexus of Remote Working and Travel Mobility," Information Technology and Tourism, vol. 22, 2020, pp. 329-334.

[15] I. Reichenberger, "Digital Nomads: A Quest for Holistic Freedom in Work and Leisure," Annals of Leisure Research, vol. 21, no. 3, 2017, pp. 364-380.

[16] B. Y. Thompson, "The Digital Nomad Lifestyle: (Remote) Work/Leisure Balance, Privilege, and Constructed Community," International Journal of the Sociology of Leisure, vol. 2, 2019, pp. 27-42.

[17] N. Willment, "The Travel Blogger as Digital Nomad: (Re-)Imagining Workplace Performances of Digital Nomadism Within Travel Blogging Work. Information Technology and Tourism, vol. 22, 2020, pp. 391-416.

[18] G. Richards, "The New Global Nomads: Youth Travel in a Globalizing World. Tourism Recreation Research, vol. 40, no. 3, 2015, pp. 340-352.

[19] M. Orel, "Coworking Environments and Digital Nomadism: Balancing Work and Leisure Whilst on the Move," World Leisure Journal, vol. 61, no. 3, 2019, pp. 215227.

[20] J. S. H. Von Zumbusch, L. Lalicic, "The Role of CoLiving Spaces in Digital Nomads' Well-Being," Information Technology and Tourism, vol. 22, 2020, pp. 439-453.

[21] D. Cook, "The Freedom Trap: Digital Nomads and the use of Disciplining Practices to Manage Work/Leisure Boundaries," Information Technology and Tourism, vol. 22, 2020, pp. 355-390.

[22] F. Mancinelli, "Digital Nomads: Freedom, Responsibility and the Neoliberal Order," Information Technology and Tourism, vol. 22., 2020, pp. 417-437.

[23] C. E. Hull, Y. T. C. Hung, N. Hair, V. Perotti, and R. DeMartino, "Taking Advantage of Digital Opportunities: A Typology of Digital Entrepreneurship," International Journal of Networking and Virtual Organizations, vol. 4, no. 3, 2007, pp. 290-303.

[24] N. Hair, L. Wetsch, C. Hull, V. Perotti, and Y. T. Hung, "Market Orientation in Digital Entrepreneurship: Advantages and Challenges in a Web 2.0 Networked World,"
International Journal of Innovation and Technology Management, vol. 9, no. 6, 2012, pp. 1-17.

[25] F. Sussan, and Z. Acs, "The Digital Entrepreneurial Ecosystem", Small Business Economics, vol. 49, no. 1, 2017, pp. 55-73.

[26] B. G. Glaser, Theoretical Sensitivity: Advances in Methodology of Grounded Theory, Sociological Press, Mill Valley, 1978.

[27] B. G. Glaser and A. L. Strauss, The Discovery of Grounded Theory: Strategies for Qualitative Research, Aldine Publishing Company, New York, 1967.

[28] J. Fendt and W. Sachs, "Grounded Theory Method in Management Research: Users' Perspectives," Organizational Research Methods, vol. 11, no. 3, 2008, pp. 430-455.

[29] S. Sarker, X. Xiao, X and T. Beaulieu, "Qualitative Studies in Information Systems: A Critical Review and Some Guiding Principles," MIS Quarterly, vol. 37, no. 4, 2013, pp. iii--xvii.

[30] Urquhart, C., Lehmann, H., and Meyers, M.D. (2010) Putting the 'theory' back into grounded theory: Guidelines for grounded theory studies in information systems. Information Systems Journal 20(4), 357-381.

[31] M. S. Poole, A. H. Van de Ven, K. Dooley, \& M. E. Holmes, Organizational Change and Innovation Processes: Theory and Methods for Research, Oxford University Press, New York, 2000.

[32] A. H. Van de Ven, Engaged Scholarship: A Guide for Organizational and Social Research, Oxford University Press, Oxford, 2007.

[33] H. Olga, "In Search of a Digital Nomad: Defining the Phenomenon,". Information Technology and Tourism, vol. 22, 2020, pp. 335-353.

[34] E. Ries, The Lean Startup: How Today's Entrepreneurs Use Continuous Innovation to Create Radically Successful Businesses, Crown Business, New York, 2011.

[35] P. Brickman, D. Coates and R. Janoff-Bulman, "Lottery Winners and Accident Victims: Is Happiness Relative?" Journal of Personality and Social Psychology, vol. 36, 1978, pp. 917-927.

[36] R. E. Lucas and A. E. Clark, "Do People Really Adapt to Marriage?" Journal of Happiness Studies, vol. 7, 2006, pp. 405-426.

[37] W. R. Boswell, J. W. Boudreau, and J. Tichy, "The Relationship Between Employee Job Change and Job Satisfaction: The Honeymoon-Hangover Effect," Journal of Applied Psychology, vol. 90, 2005, pp. 882-892. 